\title{
Occurrence and Identification of Basidiomycetous Fomitopsis Species-The Causal Agent of Brown-Rot in Oil Palm Elaeis guineensis in Johor, Malaysia
}

\author{
Muhammad Muhammad 1, 2, 3 , Roswanira Abdul Wahab ${ }^{3,4 *}$, Mohd Hefni Rusli ${ }^{5}$, Fahrul Huyop ${ }^{1,3}$ \\ ${ }^{1}$ Department of Biosciences, Faculty of Science, Universiti Teknologi Malaysia, 81310 UTM Johor Bahru, Johor, Malaysia. \\ ${ }^{2}$ Department of Microbiology and Biotechnology, Federal University Dutse (F.U.D), P.M.B. 7156, Dutse, Jigawa State, Nige- \\ ria. \\ ${ }^{3}$ Enzyme Technology and Green Synthesis Group, Faculty of Science, Universiti Teknologi Malaysia, 81310, UTM Johor \\ Bahru, Johor, Malaysia. \\ ${ }^{4}$ Department of Chemistry, Faculty of Science, Universiti Teknologi Malaysia, 81310, UTM Johor Bahru, Johor, Malaysia. \\ ${ }^{5}$ Plant Pathology and Biosecurity Unit, Biology and Sustainability Research Division, Malaysia Palm Oil Board, Bandar Baru \\ Bangi, 43000 Kajang, Selangor, Malaysia.
}

Article history:

Submission June 2021

Revised June 2021

Accepted August 2021

*Corresponding author: E-mail: roswanira@utm.my

\begin{abstract}
Macrofungi belonging to the family "Polyporaceae" in the phylum Basidiomycota are among the commonplace causal agents of plant diseases. In the present study, we reported the molecular characterization of a macrofungi basidiomycetous brown-rot fungal phytopathogen Fomitopsis strain MM4. The fungal phytopathogen was identified and molecularly characterized from the infected stem and tissue of oil palm (Elaeis guineensis) in Kulai, Johor. The 18S rRNA nucleotide sequence of the fungal pathogen strain MM4 showed 99\% similarity with partial sequences of Antrodia serialis maintained in the NCBI genebank database. The multiple sequence alignment and phylogenetic analysis revealed that the fungus clustered into a single branch of a phylogenetic tree; hence the fungus was designated as Fomitopsis meliae strain MM4. The pathogenicity test revealed significant differences $(\mathrm{p} \leq 0.05)$ in disease severity caused by the characterized basidiomycetous brownrot $F$. meliae fungal pathogen on oil palm seedlings. To the best of our knowledge, this is the first report of 18S rRNA F. meliae Basidiomycota brown-rot fungi infecting oil palm (Elaeis guineensis). The findings of this study thus support the diversity of pathogenic macrofungi affecting oil palm trees in Malaysia.
\end{abstract}

Keywords: Basidiomycota, Brown-rot fungi, Fomitopsis, Oil palm (Elaeis guineensis), Phytopathogen

\section{Introduction}

The West African oil palm (Elaeis guineensis) tree belonging to the polyporaceae family was first introduced into Malaysia in 1871 [1]. This tropical native plant is mainly cultivated as a source of vegetable oil and various useful purposes and is a commercially important crop in the tropical western region, particularly the South-East Asian countries. Over $90 \%$ of the world's palm oil export are produced from Malaysia and Indonesia [2], and Malaysia ranks the second-largest palm oil producer [3,1]. The total profits of palm oil production accounted for about $8 \%$ of the total
Malaysian Gross Domestic Product [2]. Malaysia's economic growth and gross national income hinges closely on the high yield production of palm oil $[4,2]$.

Unfortunately, various fungal diseases infecting oil palm trees are beginning to hinder the trees' growth and could lead to great losses in yield [5,6]. Therefore, a decline in oil palm yield followed by a profit drop in the oil palm industry is possible [5]. Among the well-reported fungal diseases affecting oil palm trees, the basal stem rot caused by Ganoderma boninense is amongst the highly

\section{How to cite:}

Muhammad M, Wahab RA, Rusli MH, Huyop F (2022) Occurrence and Identification of Basidiomycetous Fomitopsis Species-The Causal Agent of Brown-rot in Oil Palm Elaeis guineensis in Johor, Malaysia. Journal of Tropical Life Science 12 (1): 21 - 35. doi: 10.11594/jtls.12.01.03. 
destructive fungal pathogen of oil palm $[7,8]$. This disease has devastated many oil palm plantations in both Malaysia and Indonesia [8]. The high cost of replanting the oil palm trees would further reduce profits for both countries [9].

The brown-rot disease is also caused by Basidiomycete's fungi affecting the oil palm $[10,11]$. Most Basidiomycetous fungi are white-rot species, while the fungus Fomitopsis belongs to the brown-rot fungi [12]. The pathogenicity of the brown-rot basidiomycetous fungi has to do with their ability to degrade lignin of the infected plant host through an oxidative mechanism without breaking down the cellulose [13] and xylan [14]. However, there are reports on certain basidiomycetous fungi adept in breaking down the plant cell wall, including cellulose and hemicellulose [15, 16]. This fungal family depolymerizes the cellulose of plants, a necessary feature of their pathogenicity $[17,18]$.

To date, over 40 species of wood decay brown-rot Fomitopsis basidiomycetous fungi has been reported [19]. In the case of the brown-rot fungal phytopathogen of the Fomitopsis species, diverse polypores fungi possess porous, large fruiting bodies or tubes on their base. The fungi can be found on soft and hardwood plants $[19,20,21]$. They are Basidiomycetous-like mushrooms and hydnoid fungi belonging to the Genus Antroidia clade [22]. Brown-rot Fomitopsis sp. are perennial, and their growth habitat is rarely annual, and their fruiting body forms a hoof-shaped to pendulous, which vary in size from $1 \mathrm{~cm}$ to 40 $\mathrm{cm}[23,24,25]$. The fruiting body forms a redbelted conk and can be observed at the plant base or on the trunk [25]. The fungi are characterized by having sessile to effused-reflexed basidiomata, whitish to tan, or pinkish-coloured, porous surfaces. They exhibit clamped generative hypha (1.5 $-3.5 \mu \mathrm{m}$ in diameter), mostly dimitic or trimitic hyphal structures [19, 24]. Their thin-walled hyaline has smooth basidiospores, resulting in a brown rot in most vascular plants (gymnosperms). However, the fungi rarely affect flowering plants (angiosperms) [24]. Plants showing basidiomycetous fungal infection are easily recognizable by their pale yellow to brownish discoloured leaves, and the rapidly forming rot is the initial sign of the infection [26].

This study's molecular methods characterize the brown-rot Fomitopsis basidiomycetes fungal pathogen isolated from a mature oil palm tree, $E$. guineensis. So far, there is no report on Fomitopsis basidiomycetes fungus infecting this commercial crop. Hence, the study focused on the molecular characterization of the brown-rot basidiomycetous fungal phytopathogen by phylogenetic evidence and then confirmed the pathogenicity of the isolated fungus on seeds and growing oil palm seedlings.

\section{Material and Methods \\ Sample selection and collection}

Samples were collected from ten infected oil palm (E. guineensis) tissue and stem fragments, randomly selected from different FELDA Taib Andak oil palm plantation areas in Kulai, Johor, Malaysia (coordinate: $104^{0}{ }^{\prime} \mathrm{N} 103^{\circ} 36^{\prime} \mathrm{E}$ ). The samples were collected in sterilized plastic and brought to the laboratory for further analysis.

\section{Preparation of samples}

The symptomatic samples of stem and tissues collected were surface sterilized following the standard method described by $[27,26]$, with slight modifications. The samples were systematically cut into small fragments of between $0.5 \mathrm{~cm}-1.0$ $\mathrm{cm}$ and washed thoroughly rinsed with sodium hypochlorite (1\%) solution for two (2) minutes followed by a 3-minute soak in sterile distilled, twice. Then, the samples were air-dried on a Whatman no.1 filter paper before placing onto the potato dextrose agar (PDA, Oxoid Ltd, England) supplemented with streptomycin sulphate and incubated at $30^{\circ} \mathrm{C}$ for seven days.

\section{Isolation of the basidiomycetous brown-rot Fom- itopsis fungal phytopathogen and culture maintenance}

Isolation of basidiomycetous fungal phytopathogen was conducted under aseptic conditions, focusing on the oil palm stem and tissues showing the signs of brown-rot basidiomycetous diseases and symptoms. After seven days of incubation at $30^{\circ} \mathrm{C}$, the number of fragments incubated on PDA (Oxoid Ltd, England) supplemented with antibiotics showed fungal hyphal tips. Most hyphal tips exhibited morphologically different mycelium developing from these stem and tissue fragments. Each fungus was subcultured onto freshly prepared PDA plates until the pure cultures were obtained [26]. For long-term preservation, the fungal spores from pure cultures were cryopreserved in $80 \%$ glycerol and stored at $-80^{\circ} \mathrm{C}$ [28]. 
Morphological identification of the basidiomycetous brown-rot Fomitopsis fungal phytopathogen strain MM4

For the morphological characterization, the cultural traits which involve the visible observation traits of the fungal mycelia growing on PDA medium on day seven viz. The pigmentation, margin, elevation, mycelia appearances, mycelium texture, and colour of upper and lower sides of the mycelia were observed and recorded. The fungal isolates were subjected to microscopic observation for traits, such as the shape of conidia, presence, or absence of chlamydospores, branching patterns of conidiospores, and presence of septate hyphae, cuticular cells, and arthroconidia under a compound microscope (Nikon Eclipse E 200, Japan). Firstly, a minute mass of fungal mycelia on a sterilized glass slide, one drop of lactophenol staining reagent was placed using a dropper. A minute sample of the fungal mycelia was transferred onto a clean glass slide using a sterile needle to permit the lactophenol staining reagent to pass through the cell wall of the mycelia. The sample was then gently covered by a clean coverslip. The samples were visualized under a compound microscope at $100 \times$ magnification. The appearance of fungi and their morphological features were observed and recorded.

For scanning electron microscopic characterization, $5 \mathrm{~mm}$ discs of 5-day old cultures of the fungal mycelia were cut using a sterile scalpel and fixed in a modified Karnovsky fixative solution containing $2.5 \%$ glutaraldehyde: paraformaldehyde (2.5:2.5, w/v), $0.001 \mathrm{M} \mathrm{CaCl}_{2}$ in $0.1 \mathrm{M}$ sodium phosphate buffer $\mathrm{pH} 7.03$ for $24 \mathrm{~h}$ and the fixative were rinsed off three times with buffer solution, $\mathrm{pH}$ 7.0. Followed by 10-minute stepwise dehydration using increasing ethanol concentrations $(25,50,75,95$, and $100 \%, v / v)$, once for concentrations lower than $95 \%$ and twice for 95 and $100 \%$ [29]. Samples were then rinsed with distilled water three times and dried in a desiccator for $18 \mathrm{~h}$. The specimens were mounted on aluminium stubs using double-sided carbon tape and sputter-coated with gold (Au) using JEOL-1600 auto fine coater (Japan), and scanning electron micrographs of the specimens were taken on a JEOL Hitachi (Japan).

\section{Molecular identification}

Extraction of genomic DNA from brown-rot basidiomycetous Fomitopsis fungal phytopathogen

\section{strain MM4}

The fungal strains were disrupted by the beadbeating method. At the same time, DNA was extracted using the fast DNA SPIN kit (cat. No.1165600200, MP Biomedicals, Santa Ana CA) following the manufacturer's protocols. The fungal phytopathogen DNA extraction buffer was composed of $200 \mathrm{mM}$ Tris $\mathrm{HCl}, \mathrm{pH}$ 7.5, $\mathrm{NaCl} 250$ mM, EDTA 25 mM, SDS $0.5 \%$ [30]. In preparation for the extraction, the mycelia of the brownrot Fomitopsis fungal pathogen was grounded with a mortar and pestle into a fine powder in the presence of liquid nitrogen and freeze-dried [31].

Approximately $25 \mathrm{mg}$ of the ground phytopathogen fungal mycelia were suspended in an Eppendorf tube containing $250 \mu \mathrm{L}$ of extraction buffer and stir it by a pipette tip. Then, the slurry was mixed homogeneously with $175 \mu \mathrm{L}$ of phenol. A $75 \mu \mathrm{L}$ chloroform was added and mixed, then centrifuged at 20,000 $\times \mathrm{g}$ for $1 \mathrm{~h}$ in an Eppendorf tube. The top ether aqueous phase was withdrawn and transferred into an Eppendorf tube containing $12.5 \mu \mathrm{L}$ RNAase. The turbid solution was incubated for $5-10 \mathrm{~min}$ at $37^{\circ} \mathrm{C}$. The mixture was extracted with 1 volume of chloroform and centrifuged at 20,000 $\times \mathrm{g}$ for $10 \mathrm{~min}$. The upper ether aqueous phase was placed into a sterile Eppendorf tube mixed with $\sim 125 \mu \mathrm{L}$ of isopropanol. The DNA was precipitated, and the supernatant was decanted. The previous process was repeated, and the obtained pellet was rinsed with $70 \%$ ethanol followed by vacuum-drying under. The pellet was resuspended in $50 \mu \mathrm{L} 10 \mathrm{mM}$ Tris $\mathrm{HCl}, \mathrm{pH}$ 8, and then added $0.1 \mathrm{mM}$ filter sterilized EDTA. The extracted brown-rot Basidiomycetous Fomitopsis fungal pathogen genomic DNA was checked for purity. The DNA concentration was determined on a spectrophotometer (Pharmacia Biotech, Ultrospec2000 UV Visible Spectrophotometer) at 280 $\mathrm{nm}$.

\section{Polymerase chain reaction (PCR) of brown-rot basidiomycetous Fomitopsis strain MM4 ge- nomic DNA}

According to the manufacturer's protocol, the PCR reactions were performed in $20 \mu \mathrm{l}$ volumes containing $2 \mu \mathrm{l}$ of the brown-rot basidiomycetous Fomitopsis fungal phytopathogen genomic DNA according to the manufacturer's protocol (Qiagen ${ }^{\circledR}$ TopTaq Master Mix Kit). The amplification of rDNA-ITS region was carried out in a thermal cycler (Eppendorf Mastercycler ep Gradient S, 
Hamburg, Germany) and primers were ITS1 and ITS4 with initial denaturation at $95^{\circ} \mathrm{C}$ for 2 min followed by 35-cycles of denaturation at $94^{\circ} \mathrm{C}$ for $1 \mathrm{~min}$, annealing at $55^{\circ} \mathrm{C}$ for 30 seconds, and extension at $72^{\circ} \mathrm{C}$ for $2 \mathrm{~min}$. The thermal cycles were terminated by a final extension for $10 \mathrm{~min}$ at $72^{\circ} \mathrm{C}$ and maintained at $4^{\circ} \mathrm{C}$ [32]. Sterilized distilled water was used to replace the DNA template as the negative control. The universal primer used in the present study is expressed in S1.

DNA sequencing of the PCR amplification of rDNA-ITS region of brown-rot basidiomycetous Fomitopsis fungal phytopathogen strain MM4

PCR products were purified using QIAquick PCR Purification Kit (QIAGEN, Germany) and immediately sequenced by a DNA sequencer (Applied Biosystems) with primers for 18S rDNA (ITS1 and ITS4) and an automatic sequencer (Genetic Analyzer 310; Applied Biosystems) used according to the manufacturer's instructions at First Base Laboratories Sdn. Bhd. (Malaysia). The DNA sequences were analyzed and searched on the DDBJ/EMBL/NCBI GenBank using Basic Local Alignment Search Tool (BLAST) programs.

\section{Phylogenetic analysis of the basidiomycetous brown-rot Fomitopsis fungal phytopathogen strain MM4}

MEGA 8.0 (http://www.megasoftware.net/) was used for constructing an individual phylogenetic tree of the 18S rDNA gene of the closely related/ matched sequence to confirm the genera of the MM4 strain. The results showed that the strain MM4 to be a basidiomycetous brown rot-Fomitopsis fungal phytopathogen. The sequence was deposited in the GenBank database with the accession number MZ437369.

\section{Biochemical identification of the basidiomy- cetous brown-rot Fomitopsis fungal phytopatho- gen strain MM4}

The biochemical analysis of the basidiomycetous brown-rot Fomitopsis fungal phytopathogen strain MM4 used BIOLOG ${ }^{\mathrm{TM}}$ Gen III microplate to ascertain the fungus species through the "metabolic fingerprint" following the standard method [33]. BIOLOG III analysis consists of the sum of 96 carbon sources was utilized to identify the microorganisms. In our own case, it was the Fomitopsis fungal phytopathogen [34]. The BIOLOG III service was outsourced to a commercial service provider (Focus Biotech Laboratories Sdn. Bhd. Malaysia).

\section{Pathogenicity confirmatory test of the basidio- mycetous brown-rot Fomitopsis fungal pathogen strain MM4 on oil palm Elaeis guineensis}

For the confirmatory pathogenicity test, healthy oil palm seeds (commercial standard) and thirty (30) oil palm seedlings, three months old, were used in this study. The oil palm seedlings were obtained commercially from Pendang Nursery Sendirian Berhad Kedah, Malaysia. The seedlings were planted in nursery planting seed trays $(300 \times 22 \times 50 \mathrm{~mm}$ ) containing (Levingtons F2 + sand, Levingtons M2, perlite in ratio 1:1:1) and watered twice daily. Phytopathogenicity tests were conducted according to the methods described in earlier studies with slight modifications [35, 36, 37]. Following the pathogenicity test used three techniques with one untreated sample (negative control). The techniques were (i) $50 \mathrm{ml}$ of fungal pathogens spore suspension $\left(1 \times 10^{8} / \mathrm{mL}\right)$ were sprayed on leaves of each oil palm seedlings and wrapped with a clear transparent plastic bag to retain high relative humidity; (ii) a small cut were excised on the stem bole of each oil palm seedlings using a sterile scalpel and (iii) three-month-old oil palm seedlings were uprooted gently, then dipped into a beaker containing spore suspension $(2 \times$ $10^{8} / \mathrm{mL}$ ) of fungal phytopathogen, with approximately $250 \mathrm{ml}$ of the inoculum per seedling.

Then, the treated oil palm seedlings roots were kept in a planting tray containing soil and cultures of the fungal phytopathogen F. meliae [37] (iv) non-inoculant (negative control with seedlings sprayed with sterilized double-distilled water). The experiment was performed in triplicate. The progress of chlorosis/necrosis and lesions on each seedling was recorded weekly for three months. The disease rating scale used in this study was 0 5 , modified from the disease rating scale as described by another study [36, 38] (Figure 6). The mean differences of the collected data were analysed using the analysis of variance and post-hoctest Duncan's Multiple Range Test (DMRT) on the SPSS statistical software. The brown-rot basidiomycetous Fomitopsis fungal disease symptoms and its rating scale are stated in S2.

Infection in the shoots was confirmed and achieved following the method described by Sundram et al., [38] with slight modifications. For reisolation of the fungal pathogen from the 
inoculated seedling roots with pathogenic fungi by surface sterilizing with $70 \%$ ethanol for 5 minutes followed by cutting the shoots of about $1 \mathrm{~cm}$ lengths and placed on malt extract agar (MEA) (refer to S3) supplemented with antibiotics and kept at $30^{\circ} \mathrm{C}$ in an incubator for seven days. The pathogenicity test used oil palm seeds placed on PDA plate, inoculated with the fungal pathogen (50 mL) spore suspension, and incubated at $30^{\circ} \mathrm{C}$. The formed fungal mycelium was subcultured on freshly prepared PDA.

The study used a modified method described in an earlier study to evaluate the rot or spoil of the shoot tissues injury caused by brown-rot basidiomycetous Fomitopsis fungal phytopathogen after the 3-month inoculation duration [39,36]. The oil palm seedling shoots were first to cut into longitudinal sections. Then the internal shoots were observed for symptoms severity, based on the scale of 0 - 4 (scale 0 , healthy shoot with no internal decay tissue in plant shoot; scale 1, $1 \%-5 \%$ of the internal decay tissue in plant shoot were decayed; scale $2,5-15 \%$ of the internal decay tissue in plant shoot were decayed; scale 3, $15 \%$ - $50 \%$ of the internal decay tissue in plant shoot were decayed; scale 4 , more than $50 \%$ of the internal decay tissue in plant shoot were decayed). The disease severity on the oil palm seedlings caused by the brown-rot basidiomycetous Fomitopsis fungal phytopathogen was expressed as a percentage (DS $\%)$ based on a modified formula as shown in equation (1) [40, 36].

Note:

$$
D S(\%)=\frac{N \times R \times 100}{T \times M}
$$

$\mathrm{N}=$ No.of seedlings in disease rating scale

$\mathrm{T}=$ Total number of seedlings assessed

$\mathrm{R}=$ Disease rating scale

$\mathrm{M}=$ Maximum disease rating scale

Basidiomycetous Fomitopsis fungal pathogen was confirmed using Koch's postulate: in which the cross-sections of the infected tissues were placed into a plate containing PDA (Oxoid Ltd, England) and incubated at $30^{\circ} \mathrm{C}$ for seven days. The fungal strains recovered after seven days of incubation were maintained on PDA (Oxoid Ltd, England) for the subsequent study.

\section{Results and Discussions Morphology of the selected basidiomycetous brown-rot Fomitopsis phytopathogen}

The detrimental effects of plant diseases on the oil palm E. guineensis have encouraged concerted efforts to identify the fungal phytopathogens of oil palm. In this study, a total of 14 isolates of the fungal phytopathogens, Fomitopsis, which causes brown rot in oil palm E. guineensis, were morphologically identified as basidiomycetes. This was based on the presence of clamp connections or basidia/ basidiospores in the cultures (Figure 1). Among the 14 strains, only a single strain isolated from the infected stem of the oil palm tree, designated as the MM4 strain, exhibited the highest clamp connections and basidiospores. Seeing this, hence the study focused only on the MM4 strain.

Strain MM4 was fast-growing, with the mycelia completely covering the entire Petri dish within 3-7 days of incubation, forming whitish mycelia (starting from the 3rd day onwards). The fungus then turned pinkish when exposed to light. The lowermost of the colony retained the same colour of the growth medium with no visible coloration, consistent with a report by Rungjindamai and his colleagues [26]. The morphological features of the MM4 fungal strain were seen to match the characteristics of Fomitopsis species, as previously reported [26].

Further magnification $(5000 \times)$ under a scanning electron microscope (SEM) revealed distinct dimitic hyphal system patterns. Also, the clamp connections showing skeletal hyphae microscopic features were consistent with the Fomitopsis sp. (Figure 1). The micrographs matched the topological description of the above said fungal pathogen previously described by Liu et al., [41]. The dimitic and trimitic generative hyphae formed a thick wall that varies between $1.5-2.0 \mu \mathrm{m}$, the sporebearing structure (Basidia) formed a thin-walled clavate or hyaline, and the reproductive spore (Basidiospores) were also thin-walled. Pertinently, the collective fungal attributes agreed with the reported features of Fomitopsis species by Rungjindamai and his colleagues [26].

\section{Molecular identification of the strain MM4 by polymerase chain reaction (PCR) of the internal transcribed spacer (ITS) region}

In this study, by using the universal primer (ITS1 - ITS4), PCR amplification of total genomic DNA of Fomitopsis species produced a single PCR product having a 662 bp. A previous study by Nusaibah and her co-workers [42] revealed that random amplified polymorphic DNA 


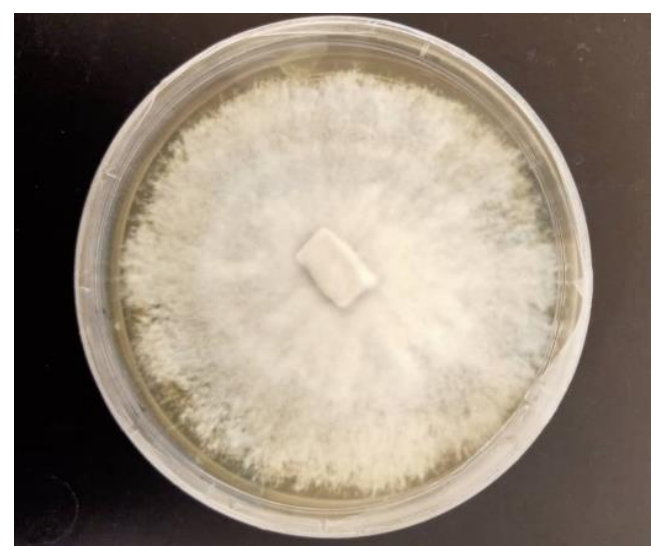

(a)

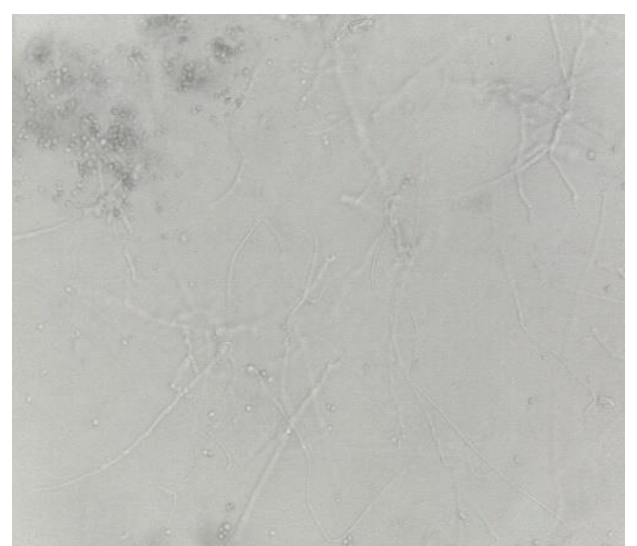

(b)

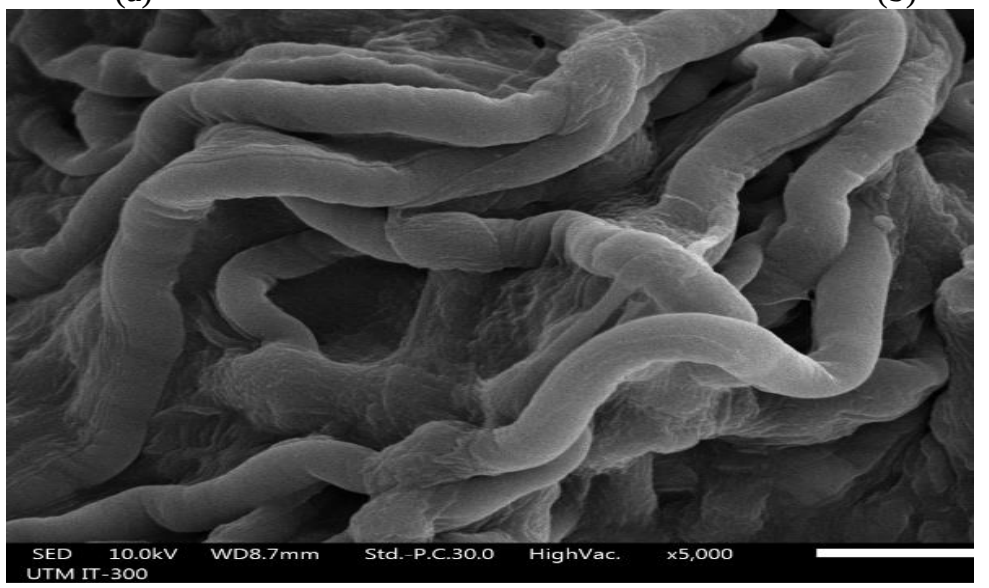

(c)

Figure 1. Morphological features of the isolated fungi Note:(a). Fungal phytopathogen was grown on PDA medium, (b). Morphological features of strain MM4 fungal pathogen under a compound microscope $(100 \times)$ and (c). SEM micrograph of dimitic hyphal system and clamp connection of fungal pathogen strain MM4 (5000× magnification).

(RAPD) and amplified fragment length polymorphism (AFLP) analysis had been proven to evaluate the variability of the basidiomycetous fungal phytopathogen strains in a population that vary in field related traits. Thus, characterization of the fungus at the species level is challenging, and the methods are very sensitive to contamination by other non-targeted fungi [42]. The primer pair, ITS1 - ITS4 was used to amplify a region from the 3 ' terminal end of the $18 \mathrm{~S}$ rDNA to the 5 ' terminal end regions [43]. The internal transcribed spacer (ITS) was used to provide tools for unambiguous identification of oil palm Fomitopsis against other species of Fomitopsis in this study. This is concurrent with the discovery reported by Liu and his colleagues [41].

The last 7 bases at the 3 ' terminal end of the aligned gene in this study were found to be CGGAGGA as described in Figure 2, and the first 21 bases in this position in the 12 Fomitopsis isolates were $5^{\prime}$ TTCCGTAGGTGAACCTGCGGA 3 ' in this study. The length of the ITS1 region of the oil palm Fomitopsis strain MM4 was $19 \mathrm{bp}$, and the length of the ITS4 was $20 \mathrm{bp}$ (S2). Two sequences that vary between the oil palm Fomitopsis in the ITS region were identified as Antrodia serialis and Aspergillus niger (outgroup) (Figure 3). The maximum parsimony tree demonstrated that the phylogeny of the Fomitopsis meliae in the phylogenetic tree was closely related to Antrodia serialis and other fungal species. The species were previously identified from various environments [22, 13].

\section{BIOLOG GEN III biochemical characterization}

A slightly modified method of Blumenstein et al., [44] was used to identify the phenotypic characteristics and metabolic potential of the brown rot Fomitopsis basidiomycetous fungal phytopathogen. In this study, analysis conducted using BIO- 


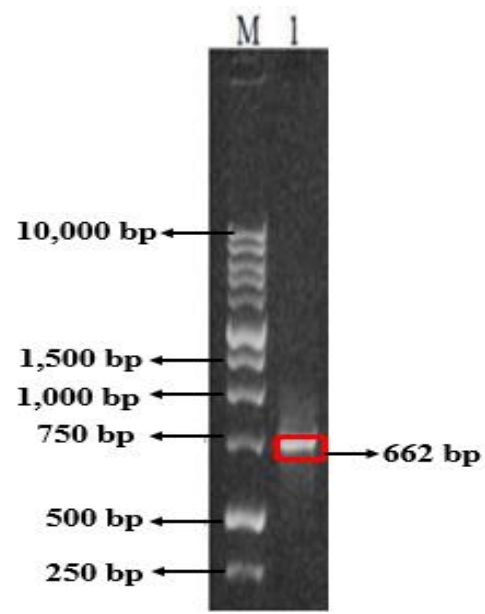

(a)

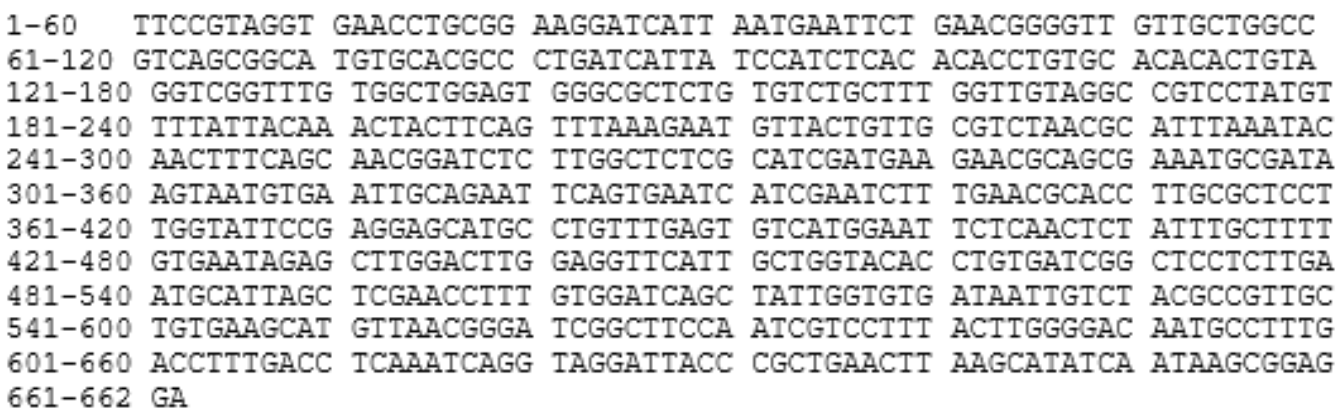

(b)

Figure 2. (a) Gel electrophoresis of PCR amplification product of gDNA of the strains MM4 on an agarose gel (1\%), lane M: $1 \mathrm{~kb}$ DNA ladder, lane 1: 662 bp amplified PCR of strain MM4, and b) the Internal Transcribe Spacer rDNA gene sequence of the strain MM4.

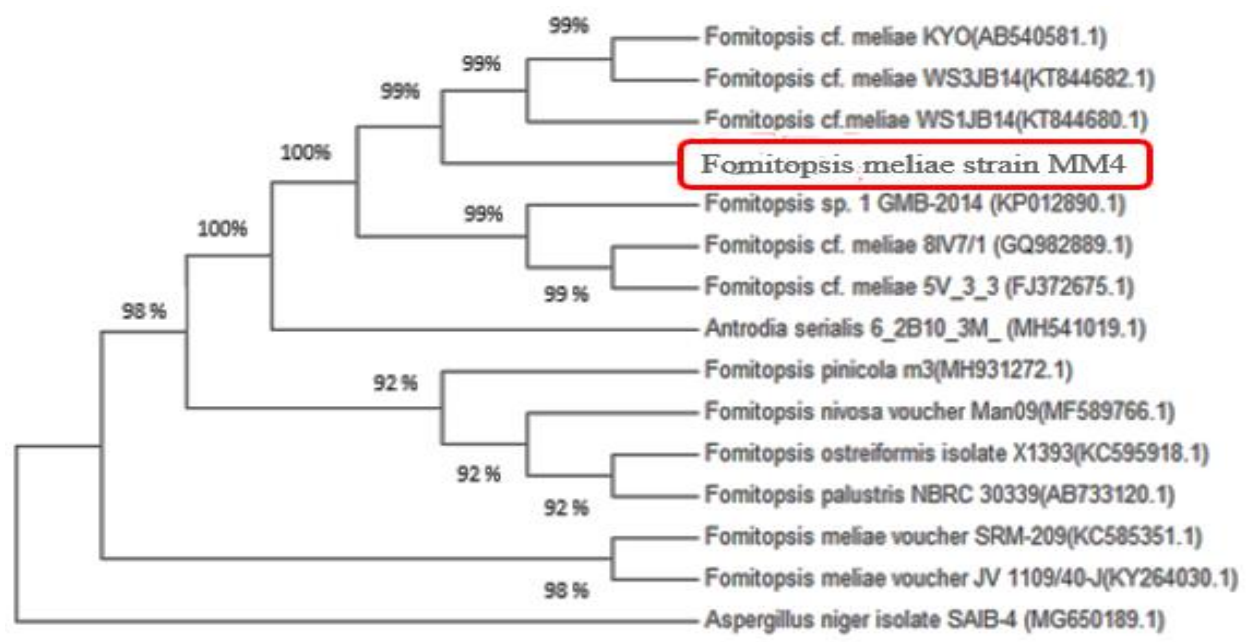

Figure 3. Phylogenetic tree of 18S rRNA sequence obtained for F. meliae MM4 using sequences of other Fomitopsis and Antrodia species from GenBank database, with Aspergillus niger species (MG650189.1) as an outgroup.

LOG GEN III ${ }^{\circledR}$ micro plate confirmatory test gives information on the identified fungal Fomitopsis to metabolize different carbon, nitrogen, phosphorous, and sulphur sources as described by Mackie 
M Muhammad, RA Wahab, MH Rusli, F Huyop, 2022 / Occurrence and identification of Basidiomycetous Fomitopsis Species

Table 1. General biochemical analysis of Fomitopsis meliae strain MM4 using BIOLOG ${ }^{\mathrm{TM}}$ GEN III Microplate

\begin{tabular}{|c|c|}
\hline Carbon sources & Results \\
\hline N-Acetyl-D-Glucosamine & + \\
\hline Adonitol & + \\
\hline D-Arabinose & + \\
\hline L-Arabinose & + \\
\hline D-Arabitol & + \\
\hline D-Cellobiose & + \\
\hline i-Erythritol & + \\
\hline D-Galactose & + \\
\hline D-Galacturonic Acid & + \\
\hline D-Gluconic Acid & + \\
\hline$\alpha$-D-Glucose & + \\
\hline D-Glucuronic Acid & + \\
\hline Glycogen & + \\
\hline m-Inositol & - \\
\hline 2-Keto-D-Gluconic Acid & - \\
\hline$\alpha$-D-Lactose & + \\
\hline Lactulose & + \\
\hline D-Sorbitol & - \\
\hline L-Sorbose & - \\
\hline Stachyose & - \\
\hline Sucrose & - \\
\hline D-Tagatose & + \\
\hline D-Trehalose & - \\
\hline Turanose & + \\
\hline Xylitol & - \\
\hline D-Xylose & + \\
\hline ү-Amino-butyric Acid & + \\
\hline Bromosuccinic Acid & - \\
\hline Fumaric Acid & + \\
\hline $\begin{array}{l}\beta \text {-Hydroxy-butyric Acid } \\
\gamma \text {-Hydroxy-butyric Acid pHydroxy- } \\
\text { phenylacetic Acid }\end{array}$ & $\begin{array}{l}+ \\
-\end{array}$ \\
\hline Hydroxyphenylacetic Acid & - \\
\hline$\alpha$-Keto-glutaric Acid & + \\
\hline D-Lactic Acid MethylEster & - \\
\hline L-Lactic Acid & - \\
\hline D-Malic Acid & - \\
\hline L-Malic Acid & - \\
\hline Quinic Acid & - \\
\hline D-Saccharic Acid & + \\
\hline Sebacic Acid & - \\
\hline Succinamic Acid & + \\
\hline Succinic Acid & + \\
\hline
\end{tabular}

Carbon sources $\quad$ Results

Succinic Acid MonoMethyl Ester +

N-Acetly-L-Glutamic Acid +

Alaninamide +

L-Alanine +

L-Alanyl-Glycine +

L-Asparagine +

Maltitol

Maltose

D-Mannitol

D-Mannose

D-Melezitose

D-Melibiose

$\alpha$-Methyl-D-Galactoside

$\beta$-Methyl-D-Galactoside

$\alpha$-Methyl-D-Glucoside

$\beta$-Methyl-D-Glucoside

Palatinose

D-Psicose

D-Raffinose

L-Rhamnose

D-Ribose

Salicin

Sedoheptulosan

L-Aspartic Acid

L-Glutamic Acid

Glycyl-L-Glutamic Acid

L-Ornithine

L-Phenylalanine

L-Proline

L-Pyroglutamic Acid

L-Serine

L-Threonine

2-Amino Ethanol

Putrescine

Adenosine

Uridine

H12 Adenosine-5'-

Monophosphate

Note: +: for positive result; -: for negative results

et al., [45]. The test authenticates the "metabolic fingerprint" for the brown-rot $F$. meliae basidiomycetous fungal phytopathogen. The carbon utilization by strain MM4 confirmed that the pathogenic fungus was the brown- rot basidiomycetous Formitopsis, an endophytic fungus as reported by Blumenstein et al., [44]. Notably, D-glucose, D- 


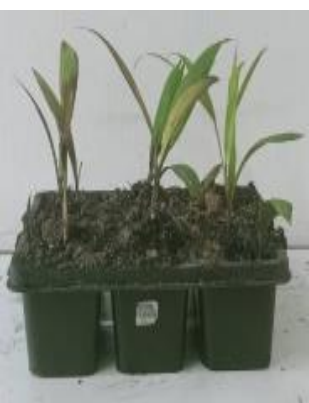

(a i)

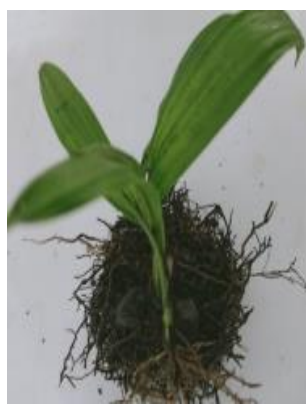

(c i)

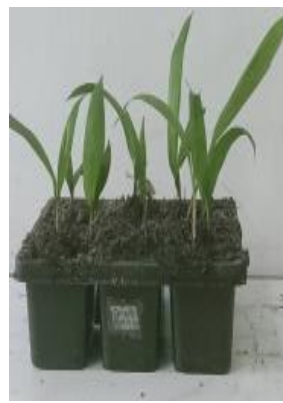

(a ii)

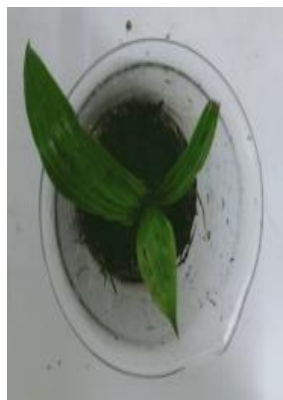

(c ii)

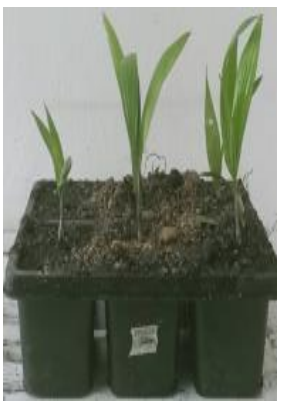

(b i)

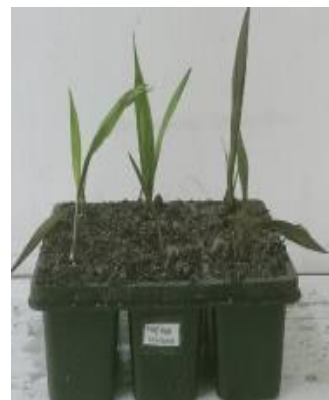

(d i)

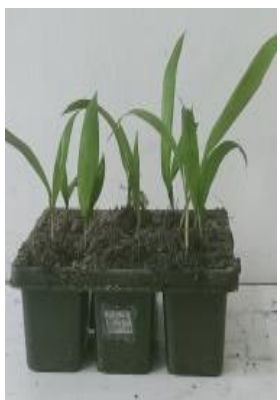

(b ii)

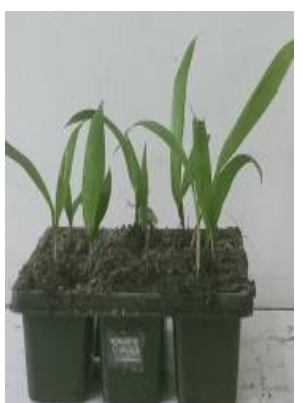

(d ii)

Figure 4. a) Effect of spraying of pathogenic fungi, Fomitopsis meliae strain MM4 spore suspension on oil palm seedlings after three months i) Treatment ii) Control, b) Effect of pathogenic fungi Fomitopsis meliae strain MM4 spore suspension on excised oil palm seedlings stem ball after three months. i) Treatment ii) Control, c) and d) Root dip system of oil palm seedlings treated with spore suspension of Fomitopsis meliae strain MM4 i) Treated sample ii) Control.

xylose and D-cellobiose were among the 47 carbon sources which the Fomitopsis MM4 strain highly metabolized. The outcome seen here concurred with the biochemical features of basidiomycetes previously described by Taylor [46].

It has been reported that, the vast habitats of filamentous fungi such as Basidiomycetous phytopathogenic fungi suggest their environmental outstanding from saprotrophy to biotrophy [47]. In this perspective, the isolated fungi $F$. meliae shows a promising production of cellulolytic and xylanolytic enzymes using a wide range of lignocellulosic biomass as substrate. Therefore, the study focused on basidiomycetous Fomitopsis, based on reports describing the fungus, on rare occasions, an opportunistic pathogen, especially on immune-compromised organisms [48,49]. The enzymes produced by the filamentous fungus are induced in the presence of polymeric substrates. The available environmental substrates are hydrolysed into their sugar monomers and metabolized by the fungi for growth [50]. The results of the D-cellobiose, D-xylose, and D-glucose metabolizing fungus strain MM4 isolated from infected mature oil palm trees are tabulated in Table 1.

\section{Pathogenicity}

A pathogenicity test was carried out by spraying the inoculum on the oil palm seedlings. The present technique was found to be more effective than incision and dip rooting methods (Figure 4). Symptoms of brown-rot progression in seedlings inoculated with $F$. meliae comprised chlorosis or necrosis of oil palm leaves, yellowing or desiccation of the oil palm leaves initiated at the tip. Gradually, the internal structure of the affected seedling softens, lesions are formed, and the plant eventually dies. The symptoms were noticeable from the first week of inoculation and till the end of 3 months observation. The brown-rot symptoms were noted on $20 \%$ of the inoculated seedlings, which were given a disease rating scale of 2 at week- 1 . The symptoms became severe over time, which caused $97 \%$ of the affected oil palm seedlings to die. Hence, a disease rating scale of 5 was given (Figure 5). The brown-rot Fomitopsis-related percentage of death and disease severity based on necrotic or chlorosis of the leaves and rotting at the oil palm seedling shoots after 3 months inoculation was estimated as $24.85 \%$ and 


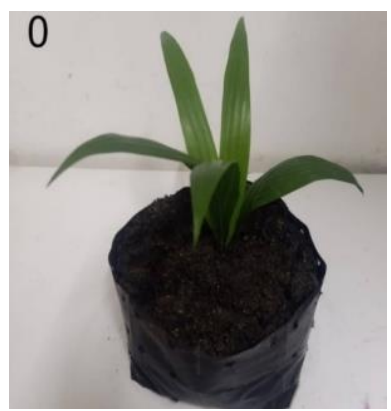

(a)

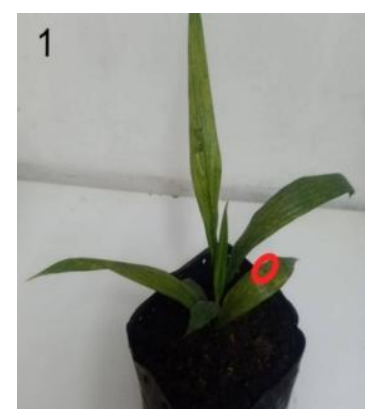

(b)

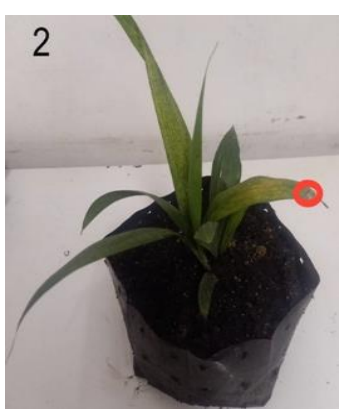

(c)

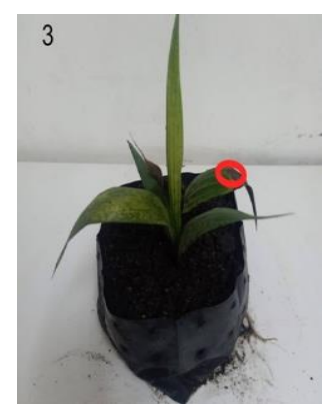

(d)

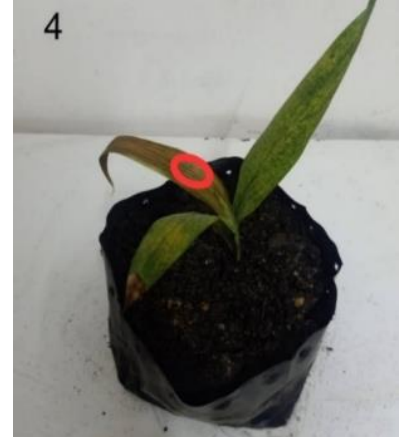

(e)

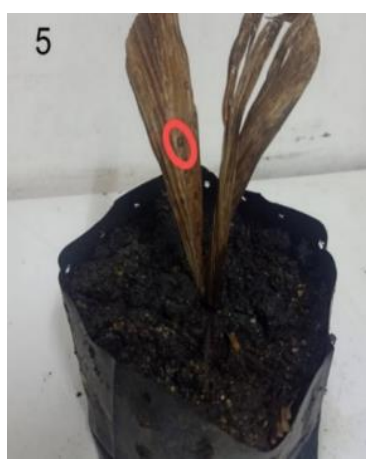

(f)

Figure 5. Disease symptoms of oil palm seedlings are rated based on the disease severity. a) scale 0: Healthy seedlings with green leaves and no softening or lesions at the shoot b) Scale 1: Healthy seedlings green leaves initiated yellowing, softening by formation of black spots and lesions at the shoot c) scale 2: Yellowing of the leaves progressed with tips wilting, softening and formation of lesions at the shoot d) Scale 3: Chlorosis/necrosis of $\geq 25-50 \%$ of the leaves and formation of lesions at the shoot e) Scale 4: Chlorosis/necrosis of $\geq 50 \%$ of the leaves, shoot softening with more lesions at the shoot $\mathrm{f}$ ) Scale 5: Complete chlorosis /necrosis, shoot softening, formation of shoot lesions and dead seedlings.

\section{$27.87 \%$, respectively.}

The three months inoculation after infecting the oil palm seedlings shoots with the F. meliae, pathogen, results of the longitudinal sections of the shoots clearly showed brown colour soft lesions, which later became fatal to the seedlings (Figure 6). On the contrary, the untreated seedlings (negative control) appeared healthy and grew well. The study then successfully re-isolated the brown-rot fungal phytopathogen F. meliae from the brown-rot of the symptomatic leaves, shoot and the seeds and inoculated with the same suspension of Fomitopsis in the plate containing PDA (Figure 7). The outcome proved that F. meliae was the causal agent of the brown-rot disease in the oil palm seedlings, which pertinently, has yet to be reported in the literature. The outcome of this study hence supported the notion that the fungus is an opportunistic pathogen on oil palm seeds, and possibly, seedlings, as well as maturing oil palm trees.

The benchmark for the cause-and-effect relationship between pathogens and plant diseases, including the species of basidiomycetous fungi such as Fomitopsis is the Koch postulate's method $[51,52,53]$. It is stated that, microorganisms must be isolated from a diseased organism and grown in axenic culture. In this study, the seedlings inoculated with $F$. meliae revealed internal symptom of shoot lesion and the F. meliae fungus was successfully re-isolated from the brown-rot symptomatic seedlings. To the best of our knowledge, this is the first report of brown-rot basidiomycetous Fomitopsis fungal phytopathogen on oil palm. In this study, the visible symptoms of the F. meliae infection on the oil palm seedlings appeared after 3 months of inoculation.

Most importantly, symptoms of the F. meliaeaffected seedlings included progressive yellowing or desiccation of the oil palm leaves, lesions in the shoots and death of the seedlings. These symptoms were not observed on the untreated seedlings (negative control). Symptoms such as wilting, yellowing of oil palm seedlings observed on the treated seedlings caused damaged to the vascular 


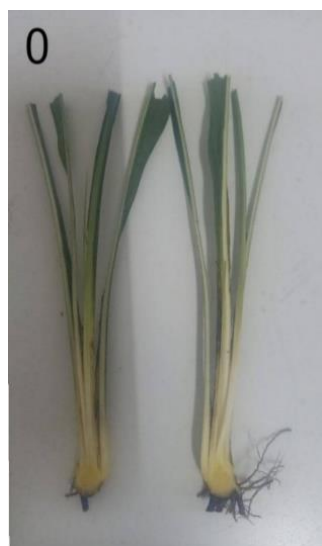

(a)

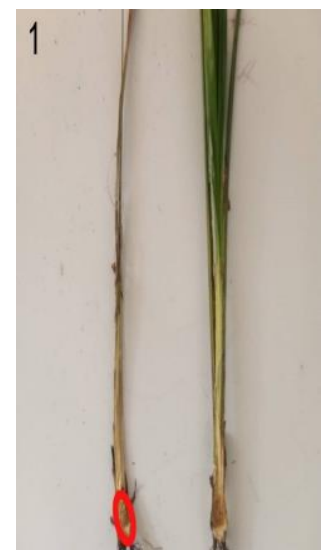

(b)

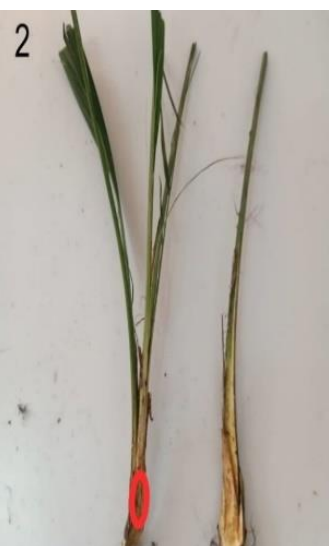

(c)

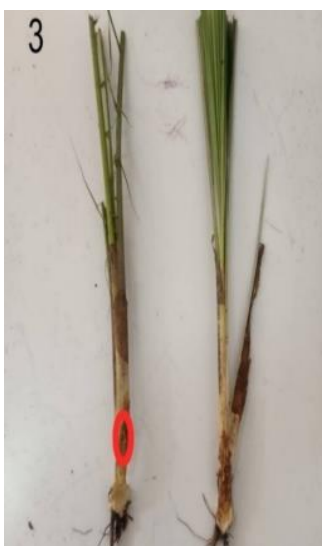

(d)

Figure 6. Longitudinal sections of oil palm seedlings shoot inoculated with Fomitopsis meliae after 3 months of inoculation. a) Un-inoculated seedlings without any symptoms b) inoculated with internal symptoms of $\sim 1-5 \%$ tissue decay, c) inoculated with internal symptoms of $\sim 5-15 \%$ tissue decay, d) inoculated sample showing internal symptoms of $\sim 15-50 \%$ tissue decay, leaves wilted and dehydrated and $\sim 97 \%$ tissue decay and the seedlings fail to germinate.

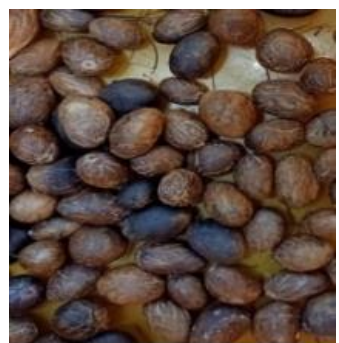

(a)

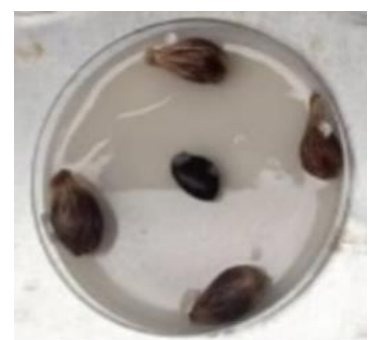

(b)

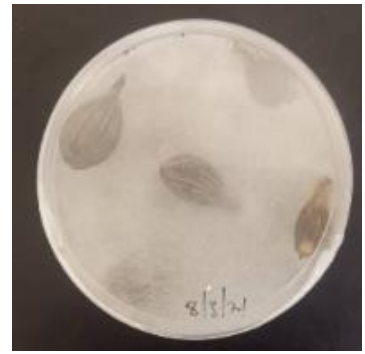

(c)

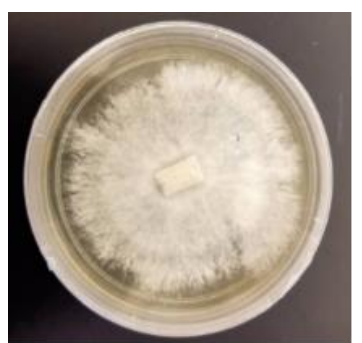

(d)

Figure 7. Re-isolated Fomitopsis meliae using oil palm seeds on agar plates. a) Untreated seeds, b) and c) are the treated plates, and d) the re-isolated Fomitopsis meliae from the brown-rot symptomatic seedlings

Table 3. The ANOVA output of treatment 1 (Leaves), treatment 2 (Shoots) compared to control (CRD)

\begin{tabular}{lllllll}
\hline Source of variation & $\begin{array}{c}\text { Degrees } \\
\text { of free- } \\
\text { dom (df) }\end{array}$ & $\begin{array}{c}\text { Sum of } \\
\text { square } \\
(\mathrm{ss})\end{array}$ & $\begin{array}{c}\text { Mean } \\
\text { square (ms) }\end{array}$ & $\begin{array}{c}\text { Standard } \\
\text { deviation }\end{array}$ & $F_{\text {observed }}$ & $\begin{array}{c}\text { Sig level (5 } \\
\%)\end{array}$ \\
\hline Treatment 1 (Oil palm Leaves) & 14 & 525.047 & 35.003 & 1.0802 & 3.459 & 2.774 \\
Treatment 2 (Oil palm Shoots) & 14 & 188.055 & 12.537 & 0.6465 & 8.107 & 5.877 \\
Untreated $\quad$ (control) & 14 & 2209.199 & 147.280 & 2.2157 & 11.142 & 10.460 \\
\hline
\end{tabular}

tissue such as xylem and phloem physiology of the seedlings [54].

All 30 tested seedlings utilized in the present study were found to be infected with Fomitopsis meliae, as apparent in the brown-rot symptoms on the seedlings in the pathogenicity test. While there were distinguishing variations in terms of the size of pathogen-inoculated shoots, there were notable differences in the progression of shoot lesions of the infected seedlings. Tissue decay and rotting internal shoot of the oil palm seedlings seen in this study corresponded to the findings of Roccotelli et al., on wood rotting of lemon citrus plant [53]. Lesions or brown-rote in the dissected pathogen-inoculated oil palm seedlings increased in size over time and affected other parts of the seedlings. Idris et al., also described a similar observation on basal stem rot fungal pathogen [51]. As a matter of fact, the study found that the prevalence of lesions in shoots between seedlings were significantly different $(\mathrm{P}<0.05)$ (Table 2).

The results of the pathogenicity test on 30 oil palm seedlings after 3 months inoculation was found to be significant $(\mathrm{P}<0.05)$. Profound 
Table 4. Univariate analysis of variance using Post-hoc Duncan’s Multiple Range Test showing the effect on the oil palm leaves

\begin{tabular}{llllll}
\hline Source & $\begin{array}{l}\text { Type III Sum of } \\
\text { Squares }\end{array}$ & $\begin{array}{l}\text { Degrees of } \\
\text { Freedom } \\
(\mathrm{df})\end{array}$ & $\begin{array}{l}\text { Mean } \\
\text { Square }\end{array}$ & $\begin{array}{l}\text { F } \\
\text { Corrected Model }\end{array}$ & $\begin{array}{l}\text { Signifi- } \\
\text { cance }\end{array}$ \\
Intercept & 20347.656 & 9 & 2008.221 & 2.774 & 0.028 \\
Effect on Oil Palm Leaves Treated & 18073.987 & 1 & 20347.656 & 28.109 & 0.00 \\
Error & 14477.867 & 9 & 2008.221 & 2.774 & 0.028 \\
Total & 52899.510 & 20 & 723.893 & & \\
Corrected Total & 32551.854 & 30 & & & \\
\hline
\end{tabular}

a: $\mathrm{R}^{2}=0.93\left(\right.$ Adjusted $\left.\mathrm{R}^{2}\right)=0.91$

Table 5. Univariate analysis of variance using Post-hoc Duncan’s Multiple Range Test showing the effect on oil palm shoot lesions

\begin{tabular}{lccccc}
\hline \multicolumn{1}{c}{ Source } & $\begin{array}{c}\text { Type III Sum } \\
\text { of Squares }\end{array}$ & $\begin{array}{c}\text { Degrees of } \\
\text { Freedom (df) }\end{array}$ & Mean Square & F & Significance \\
\hline Corrected Model & $30230.864^{\mathrm{a}}$ & 9 & 3358.985 & 5.877 & 0.00 \\
Intercept & 39613.507 & 1 & 39613.507 & 69.312 & 0.00 \\
Oil palm Shoots Treated & 30230.864 & 9 & 3358.985 & 5.877 & 0.00 \\
Error & 11430.502 & 20 & 571.525 & & \\
Total & 81274.873 & 30 & & & \\
Corrected Total & 41661.366 & 29 & & & \\
\hline
\end{tabular}

a: R2 = 0.96 (Adjusted R2 = 0.94)

Table 6. Univariate analysis of variance using Post-hoc Duncan’s Multiple Range Test showing the effect on oil palm control

\begin{tabular}{lccccc}
\hline \multicolumn{1}{c}{ Source } & $\begin{array}{c}\text { Type III Sum of } \\
\text { Squares }\end{array}$ & $\begin{array}{c}\text { Degrees of Free- } \\
\text { dom (df) }\end{array}$ & Mean Square & F & Significance \\
\hline Corrected Model & $34818.300^{\mathrm{a}}$ & 10 & 3481.830 & 10.460 & 0.00 \\
Intercept & 15254.222 & 1 & 15254.222 & 45.825 & 0.00 \\
Untreated (Control) & 34818.300 & 10 & 3481.830 & 10.460 & 0.00 \\
Error & 6324.667 & 19 & 332.877 & & \\
Total & 55619.000 & 30 & & & \\
Corrected Total & 41142.967 & 29 & & & \\
\hline
\end{tabular}

a: R2 = 0.99 (Adjusted R2 = 0.97)

changes were seen in the seedling's structure after infection with the $F$. meliae fungal pathogen. The damages seen in the oil palm shoots system (Figure 6) was the direct cause of the stunted growth and eventually death of the seedlings [36]. The ANOVA results in Table 2 showed that the mean square within and between the groups total of infected leaves of oil palm seedlings was 525.047, while the infected oil palm seedlings showing lesions on the shoots was higher at 188.055. The percentage of disease severity caused by $F$. meliae on the oil palm seedlings was 2059.918 and while the percentage related to deaths of the seedlings was 1695.625, compared to the control (2209.199). Significant differences were noted for the percentage of disease severity, death, effects on the seedlings and lesions on shoots seen in all the treatments. Collectively, with a huge variance statistic, this supported the pathogenicity of the newly identified $F$. meliae fungal phytopathogen on the oil palm seedlings in the present study. Interestingly, the statistical analysis showed that, there were significant differences in all the treatments. This was seen in the expression of large statistical mean compared to the control (Table 2). The outcome thus confirmed that the identified fungal pathogen $F$. meliae is pathogenic.

Consequently, the analysis of variance (ANOVA) affirmed the significant differences between the different treatments on the oil palm seeds. Thus, the Duncan's Multiple Range Test (DMRT) were used (Tables 4-6) to identify which 
of the group of treatment was significantly different [55]. The ANOVA output of treatment 1 (Leaves), treatment 2 (Shoots) and the control (untreated) was presented in Table 3. The degrees of freedom 14, from each treatment and mean square of each treatment viz; 35.003, 12.537, and 147.280 respectively (Table 3 ), were used for the calculation of DMRT using SPSS at 5\% (0.05) significance level.

In view of the significant differences observed between the different treatments on the oil palm seeds, the means pairs of the treated oil palms were subjected to Duncans's Multiple Range Test (DMRT) [55] to compare the means between all the treatments group (30 treatments) and compared to the control (Table 4). The univariate analysis using the Post-hoc Duncans Multiple Range Test showed the effect on oil palm leaves (Table 4 ), revealed a p value of 0.028 . This means that the symptoms of the Fomitopsis infection is significant. Likewise, the p value of 0.00 from the Duncan's univariate analysis (Table 5) signified a significantly greater symptoms severity, in references to lesions on the shoots of the infected oil palm seedlings compared to the leaves, investigated in this study. The effect of Fomitopsis infection on the treated oil palm leaves with corrected model and mean square 18073.987 and R2 of 0.93, showed that the brown-rot symptoms were lower compared to the shoot of the oil palm seedlings. In fact, the latter showed severe lesions appeared on the shoots as proven by the lower corrected model mean square of 3358.985 and an R2 of 0.96 (Figure 5). The intercept means square Post-hoc Duncan's Multiple Range Test on the pathogenicity of Fomitopsis -untreated sample was considerably lower than the means of the treated samples, which showed values of 15254.222 and R2 of 0.96 (Table 6 ). The data confirmed the profound difference in symptoms severity between the Fomitopsis-inoculated oil palm seeds compared to uninoculated ones (Figure 7). Pertinently, the values obtained from the comparison of pairs of means by DMRT (Table 4-6) were much higher in this study compared to a report by Idris et al. [51]. In short, the study proved that the Fomitopsis is a potentially serious brown-rot disease causing agent in oil palm seedlings, which should be a matter of concern to oil palm producers.

\section{Conclusion}

The present study successfully identified ba- sidiomycetous fungal phytopathogen and carried out molecular characterization from the infected stem and tissue of the oil palm (Elaeis guineensis) sample from FELDA Taib Andak, Kulai, Johor Malaysia. The characterized fungi possess all the characteristics of Fomitopsis meliae. To our knowledge, this is the first report of basidiomycetous brown rot fungi caused by Fomitopsis meliae in oil palm in Malaysia. The ANOVA affirmed that there were significance differences between the different treatments on the oil palm seedlings, in which Fomitopsis infection symptoms were more severe on the shoots compared to the leaves of the infected oil palm seedlings. Hence, it was demonstrated that the Fomitopsis is a potentially serious brown-rot disease causing agent in oil palm seedlings. Coupled with the growing ineffectiveness of chemical treatments to combat fungal diseases in oil palm, the use of alternative biological agents to curb further proliferation of fungal phytopathogens is highly recommendable.

\section{Acknowledgement}

The authors would like to acknowledge Federal Land Development Authority (FELDA) Taib Andak Kulai Johor Malaysia, for providing the infected oil palm plant stem and tissue samples.

\section{Funding}

This study was supported by the Fundamental Research Grant Scheme from the Ministry of Higher Education Malaysia (grant number FRGS/1/2018/STG04/UTM/02/2).

\section{References}

1. Onoja E, Chandren S, Razak FIA et al., (2019) Oil palm (Elaeis guineensis) biomass in Malaysia: the present and future prospects. Waste and Biomass Valorization, 10(8), 2099-2117. doi: 10.1007/s12649-018-0258-1

2. Onoja E, Chandren S, Razak FIA, Wahab R A (2018). Extraction of nanosilica from oil palm leaves and its application as support for lipase immobilization. Journal of Biotechnology, 283, 81-96. doi: 10.1016/j.jbiotec.2018.07.036

3. Mazaheri H, Lee KT, Bhatia S, Mohamed A R (2010) Sub/supercritical liquefaction of oil palm fruit press fiber for the production of bio-oil: Effect of solvents. Bioresource Technology, 101(19), 7641-7647. doi: 10.1016/j.biortech.2010.04.072.

4. Syd Ali N, Asmieda WN, Syed Sagaff SA (2021) First Report on the Fungal Pathogens Associated with Leaf Tip Blight of Oil Palm at Nursery Stage in Malaysia. Journal of Current Opinion in Crop Science, 2(1), 2739.https://jcocs.com/index.php/ej/article/view/20. 
5. Naidu Y, Siddiqui Y, Idris AS (2020) Comprehensive studies on optimization of ligno-hemicellulolytic enzymes by indigenous white rot hymenomycetes under solid-state cultivation using agro-industrial wastes. Journal of Environmental Management, 259, 110056. DOI: 10.1016/j.jenvman.2019.110056.

6. Kamarudin N, Seman IA, Masri MMM (2019) Prospects in sustainable control of oil palm pests and diseases through the enhancement of ecosystem services-the way forward. Journal of Oil Palm Research, 31(3), 381393.DOI: doi: 10.21894/jopr.2019.0030

7. Noor Azmi AN, Bejo SK, Jahari M, et al., (2020) Early Detection of Ganoderma boninense in Oil Palm Seedlings Using Support Vector Machines. Remote Sensing, 12(23), 3920-3933.

8. Siddiqui Y, Surendran A, Paterson RRM et al., (2021) Current strategies and perspectives in detection and control of basal stem rot of oil palm. Saudi Journal of Biological Sciences, 28(5), 2840-2849.

9. Rebitanim NA, Hanafi MM, Idris AS et al., (2020) GanoCare ${ }^{\circledR}$ Improves Oil Palm Growth and Resistance against Ganoderma Basal Stem Rot Disease in Nursery and Field Trials. BioMed Research International, 3063710.doi: 10.1155/2020/3063710.

10. Pinruan U, Rungjindamai N, Choeyklin R, et al., (2010) Occurrence and diversity of basidiomycetous endophytes from the oil palm, Elaeis guineensis in Thailand. Fungal Diversity, 41(1), 71-88.

11. Rytioja J, Hildén K, Yuzon J, Hatakka A De Vries, R. P., and Mäkelä, M. R. (2014) Plant-polysaccharide-degrading enzymes from basidiomycetes. Microbiology and Molecular Biology Reviews, 78(4), 614-649.

12. Krah FS, Bässler C, Heibl C et al., (2018) Evolutionary dynamics of host specialization in wood-decay fungi. BMC Evolutionary Biology, 18(1), 1-13.

13. Ruiz-Duenas FJ, Lundell T, Floudas D et al., (2013) Lignin-degrading peroxidases in Polyporales: an evolutionary survey based on 10 sequenced genomes. Mycologia, 105(6), 1428-1444.

14. Shrestha BG, Ghimire S, Bhattarai S et al., (2016) Isolation and screening of potential cellulolytic and xylanolytic bacteria from soil sample for degradation of lignocellulosic biomass. Journal of Tropical Life Science, 6(3), 93192.

15. Chukwuma OB, Rafatullah M, Tajarudin HA, Ismail N (2020) Lignocellulolytic Enzymes in Biotechnological and Industrial Processes: A Review. Sustainability, 12(18), 7282. doi: 10.3390/su12187282

16. Riley R, Salamov AA, Brown DW et al, (2014) Extensive sampling of basidiomycete genomes demonstrates inadequacy of the white-rot/brown-rot paradigm for wood decay fungi. Proceedings of the National Academy of Sciences, 111(27), 9923-9928.

17. Goodell B, Winandy JE, Morrell JJ (2020) Fungal Degradation of Wood: Emerging Data, New Insights and Changing Perceptions. Coatings, 10(12), 1210.

18. Janusz G, Pawlik A, Sulej J et al., (2017) Lignin degradation: microorganisms, enzymes involved, genomes analysis and evolution. FEMS Microbiology Reviews, 41(6), 941-962.

19. Han ML, Chen YY, Shen LL et al., (2016) Taxonomy and phylogeny of the brown-rot fungi: Fomitopsis and its related genera. Fungal Diversity, 80(1), 343-373.
20. Haight JE, Nakasone KK, Laursen GA et al., (2019) Fomitopsis mounceae and F. schrenkii-two new species from North America in the F. pinicola complex. Mycologia, 111(2), 339-357.

21. Han ML, Cui BK (2015) Morphological characters and molecular data reveal a new species of Fomitopsis (Polyporales) from southern China. Mycoscience, 56(2), 168176.

22. Ortiz-Santana B, Lindner DL, Miettinen et al., (2013) A phylogenetic overview of the antrodia clade (Basidiomycota, Polyporales). Mycologia, 105(6), 1391-1411.

23. Glaeser JA, Smith KT (2010) Decay fungi of oaks and associated hardwoods for western arborists. Western Arborist. Winter 2010:32-46.

24. Li HJ, Han ML, Cui BK (2013) Two new Fomitopsis species from southern China based on morphological and molecular characters. Mycological Progress, 12(4), 709718.

25. Scharpf RF, Goheen D (1993) Heart rots. RF Scharpf, technical coordinator. Diseases of Pacific Coast Conifers. USDA Forest Service, Agric. Handbook, 521, 150-180.

26. Rungjindamai N, Pinruan U, Choeyklin R et al., (2008) Molecular characterization of basidiomycetous endophytes isolated from leaves, rachis and petioles of the oil palm, Elaeis guineensis. Thailand. Fungal Divers, 33, 139-161.

27. Mandal P, Tiru Z, Sarkar M et al., (2021) In vitro antagonistic study of maize root colonizing fungal isolates against Fusarium moniliforme causing ear rot disease of maize. Journal of Tropical Life Science, 11(2), 133-139. http://dx.doi.org/10.11594/jtls.11.02.02.

28. Linde GA, Luciani A, Lopes AD et al., (2018) Long-term cryopreservation of basidiomycetes. Brazilian Journal of Microbiology, 49(2), 220-231.

29. Lusta KA, Kochkina GA, Sul IW et al., (2003) An integrated approach to taxonomical identification of the novel filamentous fungus strain producing extracellular lipases: morphological, physiological and DNA fingerprinting techniques. Fungal Diversity, 12, 135-149.

30. Edwards K, Johnstone C, Thompson C (1991) A simple and rapid method for the preparation of plant genomic DNA for PCR analysis. Nucleic Acids Research, 19(6), 1349.

31. Raeder U, Broda P (1985) Rapid preparation of DNA from filamentous fungi. Letters in Applied Microbiology, $1(1), 17-20$.

32. White TJ, Bruns T, Lee S, Taylor J (1990) Amplification and direct sequencing of fungal ribosomal RNA genes for phylogenetics. PCR protocols: a guide to methods and applications, 18(1), 315-322.

33. Wragg P, Randall L, Whatmore AM (2014) Comparison of BIOLOG GEN III MicroStation semi-automated bacterial identification system with matrix-assisted laser desorption ionization-time of flight mass spectrometry and 16S ribosomal RNA gene sequencing for the identification of bacteria of veterinary interest. Journal of Microbiological Methods, 105: 16-21.

34. Maurice, S., Arnault, G., Nordén, J. et al. (2021) Fungal sporocarps house diverse and host-specific communities of fungicolous fungi. The ISME Journal, 15: 1445-1457. doi: 10.1038/s41396-020-00862-1.

35. Goh YK, Marzuki NF, Goh TK et al., (2016) Mycoparasitic Scytalidium parasiticum as a potential biocontrol agent against Ganoderma boninense basal stem rot in oil 
palm. Biocontrol Science and Technology, 26(10), 13521365.

36. Naidu Y, Siddiqui Y, Rafii MY et al., (2018) Inoculation of oil palm seedlings in Malaysia with white rot hymenomycetes: Assessment of pathogenicity and vegetative growth. Crop Protection, 110, 146-154.

37. Nusaibah S, Saad G, Tan GH (2017) Antagonistic Efficacy of Trichoderma harzianum and Bacillus cereus against Ganoderma Disease of Oil Palm via Dip, Place and Drench (DPD) Artificial Inoculation Technique. International Journal of Agriculture and Biology. https://www.thefreelibrary.com/Antagonistic Efficacy of Trichoderma harzianum and Bacillus cereus...a0489239653

38. Sundram S, Meon S, Seman IA, Othman R (2015) Application of arbuscular mycorrhizal fungi with Pseudomonas aeruginosa UPMP3 reduces the development of Ganoderma basal stem rot disease in oil palm seedlings. Mycorrhiza, 25(5), 387-397.

39. Khalili E, Javed MA, Huyop F et al., (2016) Evaluation of Trichoderma isolates as potential biological control agent against soybean charcoal rot disease caused by Macrophomina phaseolina. Biotechnology \& Biotechnological Equipment, 30(3), 479-488.

40. Chaube H, Pundhir V (2005) Crop diseases and their management: PHI Learning Pvt. Ltd.

41. Liu S, Han ML, Xu TM et al., (2021) Taxonomy and phylogeny of the Fomitopsis pinicola complex with descriptions of six new species from East Asia. Frontiers in Microbiology, 12.

42. Nusaibah S, Latiffah Z, Hassaan AR (2011) ITS-PCRRFLP analysis of Ganoderma sp. infecting industrial crops. Pertanika Journal of Tropical Agricultural Science, 34(1), 83-91.

43. Utomo C, Werner S, Niepold F, Deising H (2005) Identification of Ganoderma, the causal agent of basal stem rot disease in oil palm using a molecular method. Mycopathologia, 159(1), 159-170.

44. Blumenstein K, Macaya-Sanz D, Martín JA et al., (2015) Phenotype Micro Arrays as a complementary tool to next generation sequencing for characterization of tree endophytes. Frontiers in Microbiology, 6, 1033.
45. Mackie AM, Hassan KA, Paulsen IT, Tetu SG (2014) Biolog phenotype microarrays for phenotypic characterization of microbial cells. In Environmental Microbiology (pp. 123-130): Springer.

46. Taylor J (1974) Biochemical tests for identification of mycelial cultures of basidiomycetes. Annals of Applied Biology, 78(2), 113-123.

47. Wang Q, Lin H, Shen Q, et al., (2015) Characterization of cellulase secretion and Cre1-mediated carbon source repression in the potential lignocellulose-degrading strain Trichoderma asperellum T-1. PLoS One, 10(3), e0119237. doi: 10.1371/journal.pone.0119237

48. Dresch P, D’Aguanno MN, Rosam K, Grienke U et al., (2015) Fungal strain matters: colony growth and bioactivity of the European medicinal polypores Fomes fomentarius, Fomitopsis pinicola and Piptoporus betulinus. AMB Express, 5(4), 1-14. doi: 10.1186/s13568-0140093-0.

49. Zhao Y, Liu Xz, Bai Fy (2019) Four new species of Tremella (Tremellales, Basidiomycota) based on morphology and DNA sequence data. MycoKeys (47), 75-95. , doi:10.3897/mycokeys.47.29180.

50. Amore A, Giacobbe S, Faraco V (2013) Regulation of cellulase and hemicellulase gene expression in fungi. Current Genomics, 14(4), 230-249.

51. Idris AS, Kushairi D, Ismail S, Ariffin D (2004) Selection for partial resistance in oil palm progenies to Ganoderma basal stem rot. Journal Oil Palm Research, 16(2), 12-18.

52. Idris AS, Kushairi D, Ariffin D, Basri MW (2006) Technique for inoculation of oil palm germinated seeds with Ganoderma. MPOB Information Series, 314, 1-4.

53. Roccotelli A, Schena L, Sanzani SM et al., (2014) Characterization of Basidiomycetes associated with wood rot of citrus in southern Italy. Phytopathology, 104(8), 851858. DOI: 10.1094/PHYTO-10-13-0272-R

54. de Assis Costa OY, Tupinambá DD, Bergmann JC et al., (2018) Fungal diversity in oil palm leaves showing symptoms of Fatal Yellowing disease. PloS one, 13(1), e0191884. PMID: 29370299.

55. Bewick V, Cheek L, Ball J (2004) Statistics review 9: One-way analysis of variance. Critical care, 8(2), 130136. doi: $10.1186 /$ cc2836. 
This page is intentionally left blank. 